\title{
Patent analytics as a tool for mining machines
}

\author{
Mikhail Korolev ${ }^{1}$, Sergey Nikitenko ${ }^{1 *}$, and Biswarup Neogi ${ }^{2}$ \\ ${ }^{1}$ Federal Research Center for Coal and Coal Chemistry SB RAS, Kemerovo, 650000, Russia \\ ${ }^{2}$ JIS College of Engineering, Kolkata, 741235, W.B. India
}

\begin{abstract}
The article analyses the possibility of conducting research on the competitive environment and assessing the potential effect of introducing promising technological solutions based on the use of patent landscapes even before the construction of new mining machines begins. The authors suggest that the oriented adaptation of patent analytics tools will allow solving a large-scale scientific problem. That is identifying patterns and dependences of changes in the main parameters of mining machines over time and developing a methodology for predicting and substantiating the promising parameters of various mining machines, both of one functional purpose and multifunctional ones, ensuring their efficient operation for a given period of time.
\end{abstract}

\section{Introduction}

The problems of creating and widespread introduction of promising mining machines requires a systematic approach to their design, to solving the problems of choosing the parameters of various functions in their relationship with each other and with the surrounding mining and geological environment. Each mining machine is built to perform specific workflows that reflect geotechnical requirements and capabilities. It is for this reason that, before starting the development of a machine, it is necessary to have information about the possible development ways of machines, similar in functionality, to correctly choose and justify their parameters. Such information can be obtained only on the basis of modeling work processes and predicting the parameters of the ma-chine, the totality of which determines the potential ability to perform its functions in accordance with the purpose [1].

At the first stage, the creators of mining machines are faced with the dilemma of "primacy". That is if the emergence of new geotechnologies determines the functional set of new mining machines, or the working processes incorporated in the new ma-chines make it possible to implement technologies for developing hard-to-recover (or not previously recoverable) mineral reserves. In fact, this dilemma turns into an almost insoluble trilemma, taking into account one more feature. That is the phenomena that shape the image of the mining industry in the coming years. It deals with consumer preferences, unsatisfied consumer demand and other purely market conjuncture elements of the economic and political life of society.

\footnotetext{
*Corresponding author: nsm.nis@mail.ru
} 
According to the authors, one of the possible tools for predicting the development of working processes in mining machines, taking into account the external environment, can be patent analytics, the results of which make it possible to update the directions of designing mining machines at the earliest stages.

\section{Terms and definitions used in the article}

Patent analytics (PA) is a set of methods, search and analytical tools, competencies designed to most effectively extract new knowledge from primary patent data that is useful for making managerial decisions in various industry areas and at different levels of management including state, regional, and micro- and macroeconomic levels. Pa-tent analytics can provide insight into the commercial interest in a technology.

Patent landscape (LP) is an in-depth study of innovative products, promising technologies, research and development directions based on patent data in relation to the technological priorities of an organization, defined in the Innovative Development Programs or Strategies for Scientific and Technological Development of an organization.

Patent research (PR) is research of the technical level and trends in the development of objects of economic activity, their patentability, patent purity, competitiveness (efficiency of use as intended) based on patent and other information [2].

An analytical presentation is any form of displaying patent information in various aspects (temporal, territorial, thematic, etc.). As analytical representations, various forms of visualization (2-D or 3-D) can be used presented in the form of graphs (line graph or density graph), diagrams (pie chart, radial chart, Sankey chart), cluster and thermal maps $[3]$.

\section{Main part}

Patent research, the results of which can be presented in the form of patent landscapes, is one of the actively developing methods in the last ten years for the effective determination of trends in technological development.

The patent landscape, as a rule, is developed within the framework of a certain branch of the economy or a direction of the technology, while patent research is limited to the economic activity of the subject and its competitive environment. For this reason, in the algorithms for the development of the patent landscape, there is no stage of conducting a study of the competitive environment and preparing, on the basis of these studies, conclusions and recommendations for further activities of an economic entity [3].

Another difference between the patent landscape and the patent research is the directions of their application. The patent landscape is developed to analyze the technological situation related to a specific issue and allows the relevance of the R\&D direction to be determined at the earliest stages. The results of patent research are used in the development of documents related to the activities of an economic entity and the rationale for its decisions [2]. For this reason, the patent landscape differs from the patent research by the presence of an element of information visualization to facilitate its perception and decision-making based on it.

The authors have studied the chronology of the development of patent research methodologies. Before creating patent landscapes as separate forms of patent analytics presentation, the analytical information on various industry technologies had been published in the World Patent Information Journal, in the materials of various scientific conferences on patent analytics, for example, EPOPIC, IPSDM and ICIC, which are relevant to present. In addition, the commercial patent search systems such as Derwent, 
Orbit, Lexis, Pat Seer, Pat Base, etc. developed, providing patent analytics services. Also, for the exchange of patent information knowledge, there were specialized non-commercial resources and forums, for example, the PATENT INFORMATION USERS GROUP (PUIG).

The emergence and active development of the patent landscape as a separate form of the patent analysis began in the 2010s. The most significant author of the time was Tony Tripp, the author of Guidelines for Preparing Patent Landscape Reports for the World Intellectual Property Organization (WIPO), published in 2014. Following this methodology, WIPO has been developing patent landscapes for 7 years on a commercial and non-commercial basis. Non-commercial patent landscapes are published on the WIPO website.

In modern conditions, the patent landscape as a patent analytics tool is used and developed in various branches of technology and science. Researchers from the Center for Scientific and Technical Expertise of the IPEI RANEPA under the President of the Russian Federation, N.G. Kurakova, L.A. Tsvetkova and V.G. Zinov analyzed the patent landscape of the Russian Federation in terms of the structure of applicants and patent holders; they compared this structure with the structures of other countries. As a result, they identified a distinctive feature of Russia in the structure of applicants, and noted trends in the development of science and technology in the country as a whole [4].

The article [5] analyzes the state of the institutional infrastructure of patent research in the Russian Federation in order to identify the possibilities of introducing modern patent analytics tools into the activities of various organizations. The main elements of this infrastructure have been identified and investigated, namely: specialists in this field; existing educational services in the field of patent analytics and construction of patent landscapes; sources of patent information, both commercial and free; organizations offering services for the construction of patent landscapes. Publicly available databases have been considered in detail with the aim of investigating the possibility of use by a wide range of people. The volume of structured data downloaded from patent information public databases such as Espacenet, Patent Scope, Google Patents has been compared. The problems that arise when using non-commercial databases of patent information have been identified; ways to overcome them have been considered.

The article [6] considers the methodology for the development of sectoral patent landscapes, which are a comprehensive tool for determining scientific and technological priorities and researching the competitiveness of promising technologies, products and services.

O.V. Yena has analyzed corporate patent analytics by industry as well. His work highlights the issues and challenges associated with patent analytics. The patent landscape analysis identifies emerging intellectual property risks, provides comparative patent portfolio analysis, monitors competitor technology development efforts, and predicts technology commercialization. In his opinion, the obstacles to effectively transferring the strategic results and conclusions of the patent landscape and patent analytics are:

- the imbalance between the topic of the patent landscape research and the specific technological priorities of the company

- an excessively high level of generalization of the results and conclusions of the patent landscape.

The FIPS project office implements the following three techniques to overcome the above problems:

- corporate knowledge modeling

- deep technical analysis based on the knowledge model

- "analytics based on insights" approach [7].

N.V. Popov and N.M. Shischak in their work "Patent analytics factory. Mature patent analytics production processes" note that the industry patent landscape is less and less used 
separately, and complex solutions are used for patent analytics, including different combinations of analytical products. So, recently the most popular has been the product that combines the industrial patent landscape and patent technological intelligence. The combination of products from the industry patent landscape with monitoring of new technical solutions is popular as well. This combination allows to update patent collections at any frequency and prepare up-to-date analytics based on an ongoing search strategy.

The work also highlights the key processes that distinguish the products of the Patent Analytics Factory, such as:

- the subject area modeling

- search, including the development of multilingual dictionaries of keywords and combinations of keywords

- collecting and tagging

- generating analytics

- interpretation, conclusions and recommendations.

In the work, an element of visualization of the results of patent analytics is separately highlighted in the form of infographics applied to a poster of size A2 or A1 [8].

The work "Modern Practice of Patent Analytics" by N.V. Zelenkina, D.S. Pavlikova and F.A. Batanov presents the concepts and key differences between the patent analytics, the patent research and the patent landscape. According to the authors' definition, the patent landscape is an in-depth study of innovative products, promising technologies, research and development directions based on the patent data in relation to the technological priorities of an organization, defined in the Innovative Development Programs or Strategies for Scientific and Technological Development of organizations [3].

As mentioned above, the main difference between the patent research and the patent landscapes is the object of research. The focus of the patent research is on one particular invention. The patent research is based on determining the technical level, novelty and patentability of an invention in question, and analyzing the competitive environment in this area.

Meanwhile, the focus of the attention of the patent landscape is the technological and logical area as a whole, which makes it possible to comprehensively analyze a much larger array of information in comparison with the patent research. In addition to the volume of analyzed data, the patent landscape is also significantly different in the form of results presentation. The patent landscape consists of a large number of analytical representations and descriptions to them, which make it possible to draw conclusions that are valuable to the customer, visual and understandable [3].

The work of A.I. Litvinov, S.V. Murashova, D.A. Zhuravlev and E.V. Medvedev reveals the role of the patent landscapes in making managerial decisions. They note that the patent landscape manifests itself as an effective analytical tool at all stages of management decision-making and becomes the basic element of the management system [9].

Taking into account the methodology developed by Tony Tripp for WIPO, commercial organizations and patent offices in different countries have worked out their own methodology for constructing patent landscapes. Thus, in 2016 based on the WIPO methodology, Rospatent developed Guidelines for Preparing Patent Review Reports (Patent Landscape), approved by the order of Rospatent no. 8 dated January 23, 2017. The authors compare the stages of the patent landscape development according to the FIPS and WIPO methodologies and stages of the patent research in accordance with GOST R 15.011-96 "Patent Research. Content and procedure" (Table 1).

In the given methodologies and GOST, the algorithm for conducting research and analytical work is presented. The key differences between the WIPO patent landscape development methodologies and the FIPS office project from GOST are the areas of their application. The patent landscape is an analytical tool that allows to determine the 
technological context of any investigated problem, invention or solution in the field of intellectual property.

Table 1. Comparison of the stages of patent landscape development using different methodologies.

\begin{tabular}{|c|c|c|}
\hline FIPS project office methodology & WIPO Methodology & GOST R 15.011-96 \\
\hline $\begin{array}{l}\text { 1.Defining the scope and } \\
\text { boundaries of the patent } \\
\text { landscape }\end{array}$ & \multirow[t]{3}{*}{ 1.Planning } & $\begin{array}{l}\text { 1.Determination of patent research } \\
\text { tasks, types of research and } \\
\text { methods of their conduct and the } \\
\text { development of a task for } \\
\text { conducting patent research }\end{array}$ \\
\hline 2.Developing a subject model & & 2.Determination of requirements \\
\hline \multirow[t]{2}{*}{$\begin{array}{l}\text { 3.Developing a search strategy } \\
\text { and conducting a search }\end{array}$} & & $\begin{array}{l}\text { for the search for patent and other } \\
\text { documentation, development of } \\
\text { search regulations }\end{array}$ \\
\hline & $\begin{array}{l}\text { 2.Conducting a patent } \\
\text { search }\end{array}$ & $\begin{array}{l}\text { 3.Search and selection of patent } \\
\text { and other documentation in } \\
\text { accordance with the approved } \\
\text { regulations and preparation of a } \\
\text { search report }\end{array}$ \\
\hline $\begin{array}{l}\text { 4. Quality control of patent } \\
\text { collections }\end{array}$ & \multirow[t]{2}{*}{$\begin{array}{l}\text { 3.Preparing data for } \\
\text { analytics }\end{array}$} & \multirow[t]{5}{*}{$\begin{array}{l}\text { 4. Systematization and } \\
\text { analysis of selected documentation }\end{array}$} \\
\hline 5.Forming analytical ideas & & \\
\hline \multirow{4}{*}{$\begin{array}{l}\text { 6.Expert interpretation of } \\
\text { analytical views }\end{array}$} & 4.Statistical analysis & \\
\hline & $\begin{array}{l}\text { 5.Additional statistical } \\
\text { analytics }\end{array}$ & \\
\hline & $\begin{array}{l}\text { 6.Additional types of } \\
\text { analysis }\end{array}$ & \\
\hline & & $\begin{array}{l}\text { 5. Substantiation of solutions to } \\
\text { problems by patent research; } \\
\text { substantiation of proposals for } \\
\text { further activities of an economic } \\
\text { entity, preparation of conclusions } \\
\text { and recommendations }\end{array}$ \\
\hline $\begin{array}{l}\text { 7. Compilation of a summary } \\
\text { report }\end{array}$ & $\begin{array}{l}\text { 7.Writing the report and } \\
\text { appending the data }\end{array}$ & $\begin{array}{l}\text { 6.Formation of research results in } \\
\text { the form of a patent research report }\end{array}$ \\
\hline
\end{tabular}

Compared to the FIPS methodology, the WIPO methodology has more elaborated stages, each of which includes various examples of their implementation, which makes it a complete instruction for self-development of patent landscapes. The methodology of the FIPS project office, presented as a result of adaptation of foreign experience, is a significantly condensed version of the WIPO methodology, preserving the general algorithm and structure, but without delving into the details of the implementation of each stage of landscape development, which, on the one hand, creates space for creativity, but, on the other hand, there is room for mistakes, ambiguous interpretation of stages and the possibility of omission of essential elements when conducting research and analytics.

Despite the fact that the FIPS methodology was developed under the influence of the WIPO methodology, work in this direction began even before its publication. This was due to the growing interest in the international practice in a modern analytical tool and there was a need to adapt the existing world developments to the Russian realities. 
The adaptation to the Russian specifics consisted in the fact that FIPS noted the use of the Russian patent information systems for patent statistics, as well as the fact that particular attention was paid to the specifics of the standardization of the names of Russian companies; that was a problem that was not solved anywhere else. Scenarios for identifying and analyzing intellectual property objects at the regional level were also proposed, since at that time the regions did not have the opportunity or knowledge of how to independently obtain and track the activity of applicants at the regional level. In addition, it was shown how to work in a package with the Russian legal status, namely, notices and current legal states, dragging the decisions of the Chamber for Patent Disputes and a number of other experiments. It is also important to note that the development of the FIPS methodology is based not only on the adaptation of foreign experience, but also on previous Soviet and Russian developments in the field of patent analytics.

The FIPS patent landscape development methodology introduced into the workflow revealed a number of disadvantages both in the domestic methodology and in the WIPO methodology, which prompted the need to evolve. The focus of analysis shifted from the unique properties of patent information to analysis of technology groups, companies as a whole (portfolios) and technology transfer. Later, in the course of the practice of the FIPS project office, the methodology of the FIPS project office has been formed, not approved by Rospatent, but used as a basis for the development of patent landscapes in Russia.

\section{Conclusion}

Based on the above, it can be concluded that the question of choosing a methodology for developing patent landscape or conducting patent research directly depends on the needs of the customer. Conducting a patent research study is relevant when it is necessary to conduct a study of the competitive environment and evaluate the potential effect of introducing a technological solution into work processes of enterprises. The use of patent research is relevant even before the start of $\mathrm{R} \& \mathrm{D}$; it is necessary to choose the most promising direction of research or investment.

At the present stage, it is considered by the authors to be inappropriate to use the outdated FIPS methodology. The application of the WIPO methodology is possible in the early stages of studying the topic of patent landscape development due to its sophistication and richness of examples, but the information presented in it is not sufficient for the development of full-fledged patent landscapes. The use of exclusively the methodology of the FIPS project office is the most relevant for the Russian realities, but it is not a fullfledged guarantee of the compliance of the finished patent landscape with the customer's expectations. According to the authors, the most effective methodological base for the development of patent landscapes will be the contractor's own developments or a comparison of the methodology of the FIPS project office and the WIPO methodology.

It is believed by the authors that the oriented adaptation of patent analytics tools will allow to solve a large-scale scientific problem $[1,12,13,14]$. That is to identify patterns and dependences of changes in the main parameters of mining machines in time and to develop a methodology for predicting and substantiating the promising parameters of various mining machines both one-functional and multifunctional purpose, ensuring their effective operation for a given period of time. At the same time, it is important to solve the problem of combining promising parameters into a representative information array, taking into account the historical period sufficient to ensure the required forecast reliability. 


\section{References}

1. Y.M. Radkevich, "Methodology for predicting the parameters of mining machines: (case study of long-wall top coal caving)", abstract of $\mathrm{PhD}$ of Technical Sciences diss., 05.05.06, Moscow State Mining University, ill. RSL OD, 9 93-2 / 3919-7, 36 p. (1993)

2. GOST R 15.011-96, System for the development and production of products. Patent research. Content and procedure: state standard of the Russian Federation", January 30, 1996, no.40, introduced 1996-01-01 (2010)

3. N.V. Zelenkina, D.S. Pavlikova, F.A. Batanov, Intellectual Property. Industrial property, 6, 15-24 (2019)

4. N.G. Kurakova, L.A. Tsvetkova, V.G. Zinov, Economics of Science, 1, 64-79 (2016)

5. T.G. Maksimova, S.R. Patrov, et al., Innovations, 7 (261), 19-27 (2020)

6. O.V. Ena, N.V. Popov, Methodology for the development of patent landscapes of the FIPS Project Office, 1 (014), 28-33 (2019)

7. O.V. Ena, Abstracts of the participants of the XXIV International Conference of Rospatent, 78-82 (2020)

8. N.V. Popov, N.M. Shishchak, Abstracts of the participants of the XXIV International Conference of Rospatent, 83-90 (2020)

9. A.I. Litvinov, S.V. Murashova, et al., Economics. Law. Innovations, 4 (1), 5-8 (2018)

10. A. Trippe, Guidelines for Preparing Patent Landscape Reports (2015) www.wipo.int/edocs/pubdocs/en/wipo_pub_946.pdf

11. Rospatent, Guidelines for Preparing Patent Review Reports (Patent Landscape) (2017) www.docs.cntd.ru/document/456040849

12. P.D. Krestovozdvizhensky, V.I. Klishin, et al., Gornyi Zhurnal, 6, 107-115 (2014)

13. V.I. Klishin, S.M. Nikitenko, et al., Gornyi Zhurnal, 12, 89-92 (2014)

14. L.T. Dvornikov, V. A. Korneev, et al., Gornyi Zhurnal, 1, 22-26 (2018) 